\title{
Socially facilitated drinking behavior in chicks (Gallus domesticus): Relative effects of drive and stimulus mechanisms
}

\author{
JOSEPH J. FRANCHINA, ANTOINETTE B. DYER, \\ STEPHEN J. ZACCARO, and ALLAN H. SCHULMAN \\ Virginia Polytechnic Institute and State University, Blacksburg, Virginia
}

\begin{abstract}
The drinking behavior of individual chicks $(n=168)$ was studied in two discrimination situations when the individual was alone or with an audience of merely present (not drinking) or coacting (drinking) conspecifics. In one discrimination task, a familiar and an unfamiliar drinking tube (FU) were presented simultaneously; in the other discrimination task, two unfamiliar tubes (UU) were presented. The coacting audience received a familiar and an unfamiliar tube; their familiar tube was always unfamiliar to the subject. Subjects drank more when conspecifics were present, intake being highest in the presence of coacting conspecifics. Intake was higher in the FU discrimination than in UU. However, in the UU discrimination, individuals that were tested with coactors drank most of their total intake from the tube that was similar to the coactors' familiar tube. In the FU task, individual subjects drank mostly from their familiar tube in each social condition. However, this effect was smaller for those tested with coacting conspecifics than for those tested with merely present conspecifics.
\end{abstract}

Zajonc's $(1965,1980)$ theory of social facilitation proposes that the mere presence of conspecifics is a source of arousal (general drive) which energizes an individual subject's behavior. If the subject's dominant (most likely) response is appropriate to the situation or task, the presence of conspecifics facilitates performance. If the subject's dominant response is inappropriate (or irrelevant), the presence of conspecifics impairs performance.

Zajonc's (1965) drive theory is viewed as the most parsimonious account of how conspecifics affect a subject's performance (Geen \& Gagné, 1977, p. 1283). Nevertheless, this analysis does not preclude the audience's exerting a stimulus/directive influence on the subject. The audience may provide response-relevant information to the subject or, perhaps, it may elicit particular responding from the individual (e.g., Church, 1968). For example, pecking behavior by real or simulated conspecifics has been shown to facilitate pecking in individual chicks (Strobel \& MacDonald, 1974; Tolman \& Wilson, 1965; Turner, 1964); barpressing by conspecifics has mitigated barpressing in individual rats (Zentall \& Levine, 1972; Strobel, 1972); and the familiarity/unfamiliarity of conspecifics has reliably affected the quality and quantity of the subject's pecking behavior, vocalization, and response immobility (Rajecki, Kidd, \& Ivins, 1976).

Although conspecifics may influence an individual's behavior by means of drive and/or stimulus mechanisms, the relative impact of these mechanisms on an individual's

These data were presented at the Southeastern Psychological Association meeting, New Orleans, 1984. Requests for reprints should be addressed to the first author at Department of Psychology, Virginia Polytechnic Institute and State University, Blacksburg, VA 24061. behavior in the same response situation has received little attention (e.g., Zajonc, Heingartner, \& Herman, 1969). In fact, as Geen and Gagné (1977) indicate for animal studies in particular, drive and stimulus views of audience effects are frequently competing analyses (e.g., Clayton, 1978; Rajecki et al., 1976; Rajecki, Kidd, Wilder, \& Jaeger, 1975; Strobel, 1972). If drive and stimulus properties of conspecifics do contribute separately to an individual's behavior, evidence for separability in the same response situation would facilitate evaluation of the role of each mechanism in producing audience effects.

Therefore, the present experiment studied the drinking behavior of individual chicks in a two-choice discrimination situation when the chick was alone or when it was with an audience of merely present (nondrinking) or coacting (drinking) conspecifics. Zajonc et al. (1969) and Rajecki et al. (1976) proposed that, to study the effects of an audience's stimulus properties, apart from its drive properties, on an individual's behavior, the individual should be presented with a choice between two mutually exclusive response alternatives. One alternative should demonstrably be based on audience-produced stimuli that result from the audience's performing a distinctive response. In the present experiment, subject chicks were presented with a simultaneous choice between two distinctively colored drinking tubes, spaced apart to provide mutually exclusive responses. One choice (FU) was between a familiar colored tube and an unfamiliar colored tube. The other choice (UU) was between two unfamiliar colored tubes. A familiar colored tube was one that had previously been used for water access in the subject chick's home cage. Bateson and Jaeckel (1976) reported 
that prior access to a distinctive color will result in a chick's responding more to that color than to an unfamiliar color. Thus, for a subject chick in the FU choice situation, previous familiarization procedures should yield stronger responding (drinking) toward the familiar tube than toward the unfamiliar tube. Then, according to Zajonc's viewpoint, the mere presence of an audience should augment the subject's response to the familiar tube, so that the difference in intake between familiar and unfamiliar tubes should be greater for subjects tested with an audience than for subjects tested alone. These results would provide evidence for the drive properties of conspecifics.

On the other hand, to obtain evidence for the stimulus properties of conspecifics, a distinctive response was elicited from conspecifics by presenting them with an FU choice. Previous familiarization procedures should result in the audience's drinking mainly from their familiar tube (Bateson \& Jaeckel, 1976). That tube's color was always unfamiliar to the subject chick in the present study. Thus, evidence for the stimulus properties of conspecifics would be that the subject chick in its UU task, and perhaps in its FU task, drank more from the colored tube that matched that chosen by the coacting audience (relative to the alternative tube).

\section{METHOD}

\section{Subjects}

Five hundred and four White Leghorn chicks (Gallus domesticus) were hatched from eggs obtained from the Poultry Research Center at Virginia Polytechnic Institute and State University. Upon arrival at the laboratory, the eggs were placed in a Humidare Incubator (Model No. 50 ) at $37.6^{\circ} \mathrm{C}$. After 18 days, the eggs were put into a Leahy Brooder (Model No. 416) for the 3 days prior to hatching, typically at 21 days. Twelve hours after hatching, the chicks were placed in groups of 4 into a cage, $24.76 \times 17.78 \times 17.78 \mathrm{~cm}$ (Day 1). The cage floor was $.6 \mathrm{~cm}^{2}$-ga wire mesh. Room illumination was $240 \mathrm{~lx}$, and room temperature was $30^{\circ}-33^{\circ} \mathrm{C}$. Food was always available. Of the 504 chicks, 168 served as individual subjects and 336 served as audience conspecifics. Chicks in individual and audience conditions were never cagemates.

On Days 1-6, all chicks received ad-lib access to water in 50-ml Richter-type drinking tubes. The tubes were clear or colored red or green, depending upon the chick's group assignment. Tube color was equally distributed across groups. (Analysis of the test data indicated that tube color did not account for a significant amount of variance in the results.) Beginning at $20: 00 \mathrm{~h}$ on Day 6 , all chicks were deprived of water for $12 \mathrm{~h}$ prior to testing on Day 7.

\footnotetext{
Apparatus

The test apparatus was two wire-mesh double cages (each 46.2 $\times 25.6 \times 17.78 \mathrm{~cm}$ ), which were attached at the 46.2 -cm surface to form two compartments, separated by a wire-mesh partition. Chicks in opposite compartments had visual and auditory contact but not direct, physical/tactile contact. Two apertures (each $6.4 \times$ $2.6 \mathrm{~cm}$ ) were made, $20.5 \mathrm{~cm}$ apart, in the partition. Each aperture could accommodate the spouts of two Richter-type drinking tubes. The spouts of each pair of tubes protruded into opposite compartments. The apparatus was illuminated by a 100 -W lamp, $1.0 \mathrm{~m}$ overhead and $0.25 \mathrm{~m}$ to the left. A $53.8 \times 38.5 \mathrm{~cm}$ mirror $1.2 \mathrm{~m}$ above the center of the apparatus permitted observation of the subject without the experimenter's being in the subject's visual field.
}

\section{Design and Procedure}

On Day 7, 168 chicks were assigned randomly to a $2 \times 3$ design $(n=28)$ : two discrimination-choice conditions (FU or UU) $\times$ three audience conditions (N, MP, or $\mathrm{C}$ ). In the FU discrimination, a colored tube that matched that presented in the subject's home cage on Days 1-6 (familiar) was presented simultaneously with another colored tube which had not been previously presented (unfamiliar). In the UU discrimination, two distinctive, unfamiliar (U) colored tubes were presented simultaneously. In the no-audience $(N)$ condition, the subject occupied one compartment of the apparatus and the adjacent compartment was empty. In the merely present audience (MP) condition, the adjacent compartment contained 3 waterdeprived conspecifics but no drinking tubes. MP constituted a merepresence condition in Zajonc's (1965) terms. In the coacting audience $(C)$ condition, the adjacent compartment contained 3 waterdeprived conspecifics and two water-filled drinking tubes. One tube was familiar to the conspecifics; the other was unfamiliar. The color of the conspecifics' familair tube was always unfamiliar to the subject in the latter's FU choice and was one of the two unfamiliar tubes in the subject's UU choice. Colors were counterbalanced across familiarity-unfamiliarity conditions for subject chicks and for $\mathrm{C}$ condition conspecifics. Conspecifics in the $\mathrm{C}$ condition invariably drank from their familiar tube.

For a test trial, the subject chick was placed into one compartment, thereby activating a Standard Electric timer. In the MP and $C$ conditions, the audience was placed into the adjacent compartment simultaneously with placement of the subject. A trial lasted $10 \mathrm{~min}$. The experimenter continuously observed the subject chick through the mirror. Two hand-held counters were used to record the subject chick's number of drinking responses to each tube. After a trial, all chicks were returned to the home cage.

The performance measures for each subject chick were amount drunk from each tube and number of drinking responses. Amount drunk was calculated to the nearest $100 \mathrm{mg}$, as the difference in the weight of the tube from before to after the test trial. Total intake was the amount drunk from both tubes. To measure differential responding for each subject in each choice task, percent intake was calculated as intake from Tube 1 divided by intake from Tube 1 and Tube 2 (times 100). For the FU task, Tube 1 was the familiar (home cage) tube and Tube 2 was the unfamiliar tube. For the UU task, the color of the tube designated as Tube 1 was the same as that of Tube 1 in the FU task. Evidence for differential responding toward the familiar tube (1) was a percentage score above 0.5 . A score below 0.5 would indicate differential behavior toward the other tube (2). Data analyses were $2 \times 3$ analysis of variance (ANOVA), Tukey tests, and $t$ tests, as appropriate. To assess differential responding, percent intake was evaluated with $z$ scores. Alpha level was 0.05.

\section{RESULTS}

The results for intake and number of drinking responses were essentially similar. Only intakes are reported.

Figure 1 presents mean total intake (in grams) for each choice task and audience condition. Subjects that were tested with the $\mathbf{C}$ audience drank more than did those tested with $\mathrm{N}$ audience or with the MP audience. Intake on the FU task was greater overall than that on the UU task. This finding is consistent with that observed within the FU task itself: namely, subject chicks drank more from the familiar tube than from the unfamiliar tube in each audience condition. For the $\mathrm{N}$ condition, mean intakes were $2.14 \mathrm{~g}$ from $\mathrm{F}$ and $0.50 \mathrm{~g}$ from $\mathrm{U}$. For the MP condition, intakes were $2.91 \mathrm{~g}$ from $\mathrm{F}$ and $0.21 \mathrm{~g}$ from $\mathrm{U}$. For the $\mathrm{C}$ condition, mean intakes were $3.04 \mathrm{~g}$ from $\mathrm{F}$ 


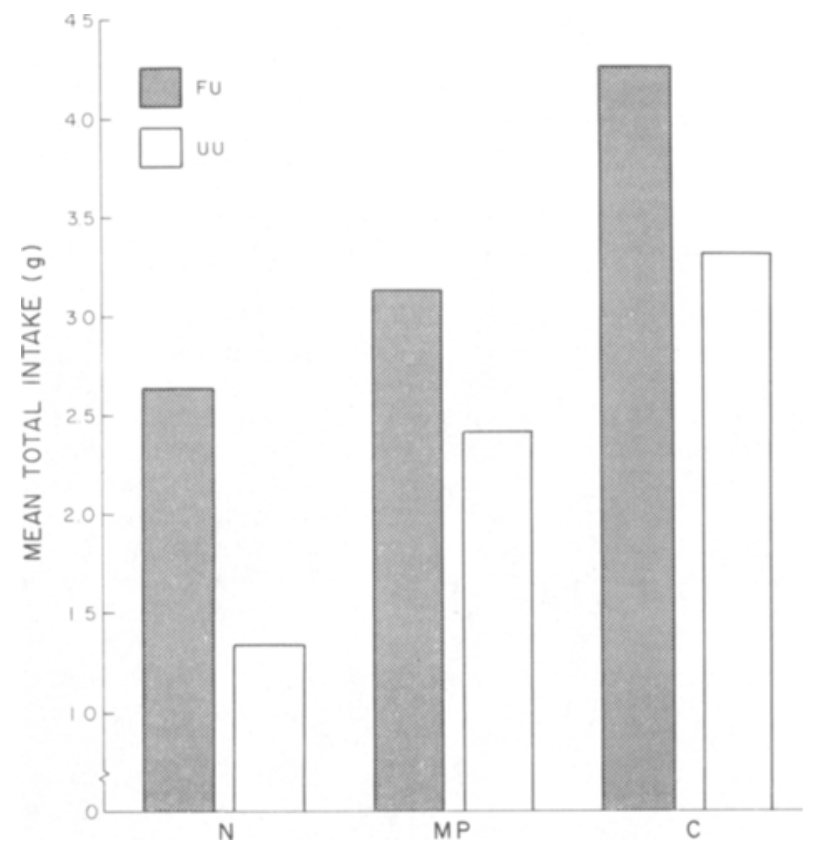

Figure 1. Mean total intake for subjects that were given a choice beween a familiar and an unfamiliar drinking tube (FU) or between two unfamiliar tubes (UU) either with no audience present (N) or with audiences of merely present (MP) or coacting (C) conspecifics.

and $1.28 \mathrm{~g}$ from $\mathrm{U}$. Tukey tests showed that the $\mathrm{F}$ versus $\mathrm{U}$ comparison was reliable in each case $(p<.05)$.

An ANOVA of the data of Figure 1 yielded reliable effects for audience condition and choice task $[F \mathrm{~s}(2,162$ and $1,162)=6.91$ and $6.05, p s<.05$ ] but not for the audience condition $\times$ choice task interaction $(F<1)$. Tukey-test comparisons showed that intake of subject chicks tested under the $\mathrm{C}$ condition differed reliably from that of those tested under the N or MP condition, which did not differ reliably.

Figure 2 shows means percent intake for each choice task and audience condition. For each audience condition, percent intake on FU exceeded 0.5 , indicating that differential responding occurred in favor of the familiar tube. In the UU choice, percent intake was about 0.5 for subjects tested under the N or MP condition, indicating nondifferential responding. However, for subjects tested under the $\mathrm{C}$ condition, percent intake on $\mathrm{UU}$ was below 0.5 , indicating that differential responding had occurred. As revealed by $z$ scores, percent intake on FU differed reliably from the 0.5 level for subjects tested under the $\mathrm{N}, \mathbf{M P}$, or $\mathbf{C}$ condition. On UU, however, a reliable effect occurred only for subjects tested under the $C$ condition. The $z$ scores were, respectively, $2.17,5.45,2.17$, and $-4.30(p s<.02,<.001,<.02$, and $<.001)$.

Figure 2 also shows that, in each audience condition, percent intake was higher on FU than on UU. The difference between FU and UU was smallest for subjects tested with no audience present and largest for subjects tested with a coacting audience. An ANOVA over all of Figure 2 yielded reliable effects for audience condition, choice task, and audience condition $\times$ choice task $\left[F_{\mathrm{s}}(2,162,1,162\right.$, and 2,162$)=44.11,6.99$, and 4.02 , ps $<.01,<.01$, and $<.05$, respectively]. Subsequent evaluations with $F$ ratios revealed reliable differences between FU and UU for subjects tested under the $C$ or MP condition but not under the $\mathrm{N}$ condition. For the UU task, ANOVA and Tukey tests showed that percent intake for subjects tested under the $\mathrm{C}$ condition differed reliably from that of subjects tested under the N or MP condition, which did not differ reliably. Finally, an ANOVA of percent intake for FU showed no reliable effect of audience conditions. However, $t$ test comparisons showed reliable differences between MP and $\mathrm{N}$ conditions $[t(27)=2.33, p<.05]$ but not between MP and $C(p>.05<.10)$.

\section{DISCUSSION}

The percent intake data reliably indicated that drive and stimulus properties of conspecifics separately affected the responding of the individual chicks. Together with these data, the total intake further suggested that the stimulus properties of conspecifics affected the individual's behavior more than did conspecifics' drive properties.

Evidence for drive effects in the percentage data was that subjects, tested with a merely present (MP) audience, showed a reliable difference in performance between FU and UU tasks, whereas subjects tested without an audience did not. Previously familiarizing the subjects with a particular colored drinking tube in the home cage presumably occasioned more drinking from that (familiar) tube than from the unfamiliar tube in the FU choice. In the

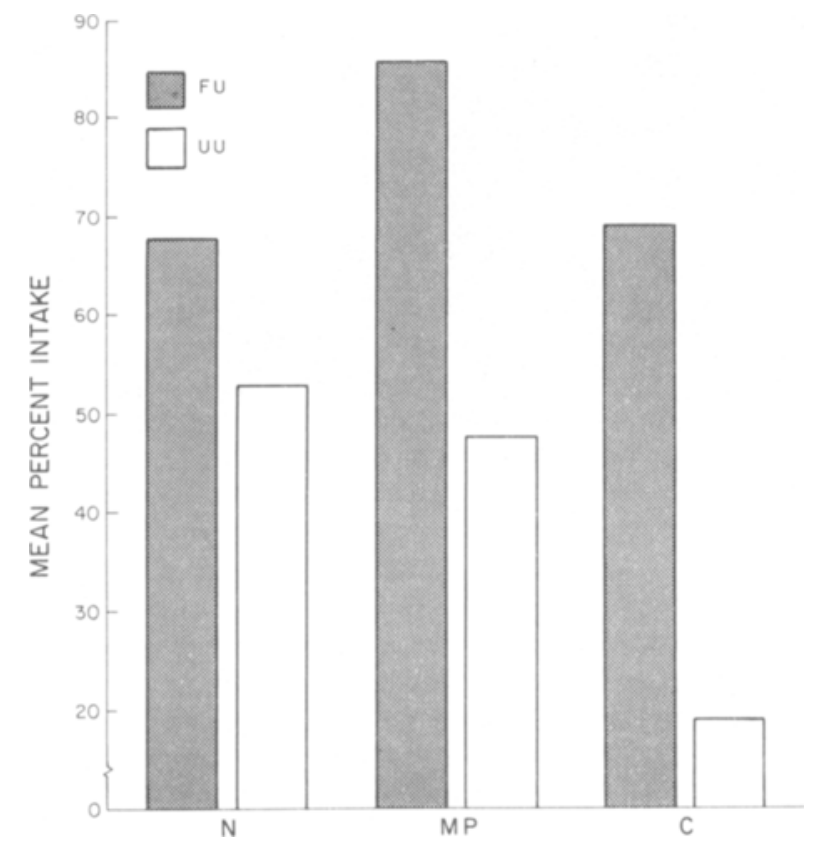

Figure 2. Mean percent intake for subjects on FU and UU tasks either with no audience present $(N)$ or with audiences of merely present (MP) or coacting (C) conspecifics. 
UU choice, drinking behavior was nondifferential because both tubes were unfamiliar to the subject. (The $z$ scores statistically confirmed these findings.) For subjects that were tested with MP conspecifics, the presence of an audience presumably served as a source of drive that augmented responding to the familiar tube and, thereby, enhanced the magnitude of differential behavior in the FU task. Consequently, percent intake on FU increased over that on UU, enlarging the FU-UU difference for subjects tested in MP condition. However, it should be noted that on total intake (Figure 1) subjects tested in MP condition did not differ reliably from those tested in N. Water deprivation and home cage drinking experience presumably made drinking a highly likely behavior in testing. A drive analysis would predict that individual subjects tested with MP conspecifics would drink reliably more than those tested without an audience. That finding did not occur. Rather, subjects that were tested with a coacting audience reliably drank the most. This finding suggests that the latter subjects were responding, in part, on the basis of audience-produced cues. Thus, the total intake data suggest that the stimulus properties of conspecifics affected the individuals' drinking more than did the conspecifics' drive properties. Furthermore, the reliable differences in total intake between MP and C conditions contradicts the view (e.g., Gardner \& Engel, 1971; Zajonc, 1980; Zajonc et al., 1969) that a coacting audience influences a subject's behavior no differently from the way in which a merely present audience does.

The percentage data that reliably evidenced the stimulus properties of conspecifics was that individual subjects tested in the $\mathbf{C}$ condition showed reliable differential responding in the UU task. Their mean percent intake differed reliably from the 0.5 level because they drank more from Tube 2 (mean intake $=3.03 \mathrm{~g}$ ) than from Tube 1 (mean intake $=0.30 \mathrm{~g}$ ). Recalculation of percent intake for Tube 2 relative to total intake yielded a percentage of 0.82 , which was reliably above the 0.5 level by $z$-score analysis. For subjects tested in the $\mathrm{C}$ condition, the color of Tube 2 matched that of the coactors' familiar tube. Thus, the percentage data suggest that the audience's drinking from its familiar tube provided response-relevant stimuli to the subject. These stimuli not only occasioned drinking behavior, and the highest total intake over all, for subjects in $\mathrm{C}$ condition (see Figure 1), but also apparently directed behavior toward a particular colored tube.

In a similar fashion, audience-produced cues could have been responsible for the lower percent intake on the FU task for subjects tested with coactors relative to those tested with merely present conspecifics. In FU, the unfamiliar colored tube in the subject's choice was the familiar tube in the coactors' choice. The audience's drinking from its familiar tube may have provided stimuli which occasioned drinking by the subject from a tube whose color matched that of the coactors' tube. In that case, the subject's drinking response would be directed toward its unfamiliar tube. Then, because of the spatial separation between the tubes, the subject's intake from its familiar tube would be decreased (relative to total intake). Consequently, on FU, percent intake for subjects tested with coactors would be less than that for subjects tested with merely present conspecifics. This analysis is only suggestive, because $\mathrm{C}$ and MP conditions did not differ reliably on percent intake for FU.

Although the percentage data for UU and FU tasks indicate that audience-produced cues influenced the subjects' behavior, the way to characterize this influence may be arguable. The audience's drinking from its familiar colored tube could have directed the subject's attention to that tube (Thorpe, 1963, p. 134). Or, perhaps, the audience's drinking in a particular location (i.e., where its familiar tube was) may have elicited approach behavior from the subject. Then, once in the vicinity of the audience, the subject imitated the audience's behavior. Tube color here may be less critical. Furthermore, the effects of social stimuli on the individual in FU and UU tasks may depend upon the presence of nonsocial cues. In the UU choice, the presence of nondifferential color cues for drinking may have made the individual more likely to respond on the basis of audience-produced stimuli. Thus, differential responding occurred for subjects in the $\mathrm{C}$ condition on the UU task. In the FU choice, the presence of differential (familiar vs. unfamiliar) color cues for drinking mitigated the impact of audience-produced stimuli. Social cues from drinking conspecifics did reduce percent intake on FU for subjects tested in the $\mathrm{C}$ condition. but these subjects still drank reliably more from their familiar tube $(3.04 \mathrm{~g})$ than from the unfamiliar tube $(1.28 \mathrm{~g})$, whose color matched that of the audience's familiar tube. Thus, social stimuli apparently were not sufficiently potent to override the influence of nonsocial cues in the environment.

In summary, this experiment provided evidence for the separable, and not necessarily antagonistic, roles of drive and stimulus mechanisms of audience effects within the same response situation. Stimulus properties of conspecifics seemed to be more influential than the conspecifics' drive properties. Furthermore, the present data suggest that the impact of social cues should be considered in relation to the situational/contextual stimuli in which social effects occur (Clayton, 1978; Davis, 1973).

\section{REFERENCES}

Bateson, P. P. G., \& JAECKeL, J. B. (1976). Chicks' preference for familiar and novel conspicuous objects after different periods of exposure. Animal Behaviour, 24, 386-390.

ChURCH, R. M. (1968). Applications of behavior theory to social psychology: Imitation and competition. In E. C. Simmel, R. A. Hoppe, \& G. A. Milton (Eds.), Social facilitation and imitative behavior (pp. 135-167). Boston: Allyn \& Bacon.

Clayton, D. A. (1978). Socially-facilitated behavior. The Quarterly Review of Biology, 53, 373-392.

DAvis, J. M. (1973). Imitation: A review and critique. In P. P. G. Bateson \& P. H. Klopfer (Eds.). Perspectives in ethology (pp. 43-72). New York: Plenum Press.

GARDNER, E. L., \& ENGEL, D. R. (1971). Imitation and social facilitatory aspects of observational learning in the laboratory rat. Psychonomic Science, $25,5-6$.

Geen, R. G., GaGné, J. J. (1977). Drive theory of social facilita- 
tion: Twelve years of theory and research. Psychological Bulletin, 84, 1267-1288.

RAJECKI, D. W., KIDD, R. F., \& Ivins, B. (1976). Social facilitation in chickens: A different level of analysis. Journal of Experimental Social Psychology, 12, 233-246.

RAJeCKI, D. W., KidD, R. F., Wilder, D. A., \& JAEGer, J. (1975). Social factors in the facilitation of feeding chickens: Effects of imitation, arousal, or disinhibition? Journal of Personality \& Social Psychology, 32, 510-518.

STrobel, M. G. (1972). Social facilitation of operant behavior in satiated rats. Journal of Comparative \& Physiological Psychology, 80, 502-508.

Strobel, M. G., \& MacDonald, G. E. (1974). Induction of eating in newly hatched chicks. Joumal of Comparative \& Physiological Psychology, 86, 493-502.

THORPE, W. H. (1963). Learning and instinct in animals. Cambridge, MA: Harvard University Press.
Tolman, C. W., \& Wilson, G. F. (1965). Social feeding in the domestic chick. Animal Behaviour, 13, 134-142.

TURNER, E. R. A. (1964). Social feeding in birds. Behaviour, 24, 1-46. ZAJONC, R. B. (1965). Social facilitation. Science, 149, 269-274.

ZaJonc, R. B. (1980). Compresence. In P. B. Paulus (Ed.), Psychology of group influence (pp. 35-59). Hillsdale, NJ: Erlbaum.

Zajonc, R. B., Heingartner, A., \& Herman, E. M. (1969). Social enhancement and impairment of performance in the cockroach. Journal of Personality \& Social Psychology, 13, 83-92.

ZENTALL, T. R., \& LEVINE, J. M. (1972). Observational learning and social facilitation in the rat. Science, 178, 1220-1221.

(Manuscript received May 24, 1985; revision accepted for publication March 3, 1986.) 